\title{
Mediterranean Diet and Healthy Ageing: A Sicilian Perspective
}

\author{
Sonya Vasto ${ }^{a}$ b Silvio Buscemi ${ }^{c} \quad$ Annalisa Barera $^{d}$ Marta Di Carlo $^{a}$ \\ Giulia Accardi $^{d}$ Calogero Caruso $^{d}$ \\ a Istituto di Biomedicina e Immunologia Molecolare, Centro Nazionale per le Ricerche, ${ }^{b}$ Dipartimento di Scienze e \\ Tecnologie Biologiche, Chimiche e Farmaceutiche, 'Dipartimento Biomedico di Medicina Interna e Specialistica, \\ and ${ }^{\mathrm{d}}$ Dipartimento di Biopatologia e Biotecnologie Mediche e Forensi, Università di Palermo, Palermo, Italy
}

\section{(C) Free Author Copy - for personal use only}

ANY DISTRIBUTION OF THIS ARTICLE WITHOUT WRITTEN CONSENT FROM S. KARGER AG, BASEL IS A VIOLATION OF THE COPYRIGHT.

Written permission to distribute the PDF will be granted against payment of a permission fee, which is based on the number of accesses required. Please contact permission@karger.ch

\section{Key Words}

Longevity · Mediterranean diet · Hormesis · Mortality $\cdot$

Nutrient-sensing pathway · Sicily

\begin{abstract}
Traditional Mediterranean diet (MedDiet) is a common dietary pattern characterizing a lifestyle and culture proven to contribute to better health and quality of life in Mediterranean countries. By analyzing the diet of centenarians from the Sicani Mountains and eating habits of inhabitants of Palermo, it is reported that a close adherence to MedDiet is observed in the countryside, whereas in big towns this adherence is not so close. This has an effect on the rates of mortality at old age (and reciprocally longevity) that are lower in the countryside than in big towns. Concerning the health effects of the diet, the low content of animal protein and the low glycaemic index of the Sicilian MedDiet might directly modulate the insulin/IGF-1 and the mTOR pathways, known to be involved in ageing and longevity. In particular, the reduction of animal protein intake may significantly reduce serum IGF-1 concentrations and inhibit mTOR activity with a down-regulation of the signal that leads to the activation of FOXO3A and, consequently, to the transcription of homeo-
\end{abstract}

static genes that favour longevity. The down-regulation of both IGF-1 and mTORC1 also induces an anti-inflammatory effect. In addition to the effects on sensing pathways, many single components of MedDiet are known to have positive effects on health, reducing inflammation, optimizing cholesterol and other important risk factors of age-related diseases. However, a key role is played by polyphenols represented in high amount in the Sicilian MedDiet (in particular in extra virgin olive oil) that can work as hormetins that provide an environmental chemical signature regulating stress resistance pathways such as nuclear factor erythroid 2-related factor 2 .

(c) 2014 S. Karger AG, Basel

\section{Introduction}

Traditional Mediterranean diet (MedDiet) is a common dietary pattern, adopted by inhabitants of countries within the Mediterranean basin, where olive trees grow. This diet was prevalent before globalization affected cultural eating patterns in these areas. MedDiet is a dietary pattern characterizing a lifestyle and culture proven to contribute to better health and quality of life, reducing the

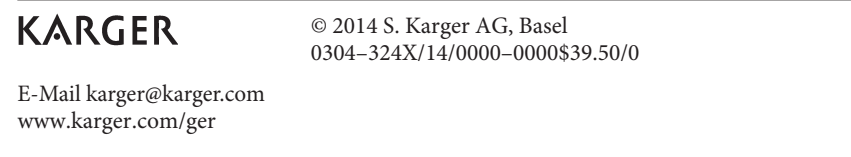

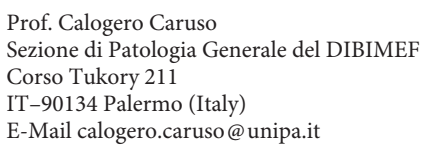

Prof. Calogero Caruso Corso Tukory 211

E-Mail calogero.caruso@unipa.it 
risk of developing age-related diseases and favouring longevity. However, even within Mediterranean countries, there are many cultural and religious differences that contribute to the diversity of dietary patterns. Therefore, the concept of 'Mediterranean diets' in general is more accurate than the concept of a specific diet in particular [1-4].

While Mediterranean dietary characteristics have changed and evolved over time, one constant, common denominator has always remained - a very special triad of foods that began in early Greek mythology. A gift given to mortal humans by Demeter, Athena and Dionysus, that was then passed on to the Romans, namely, bread, oil and wine. They are signs of a culture deeply rooted in living off the land since these products do not exist in nature by themselves, but instead have to be made, by using and combining locally grown ingredients. Mediterranean food culture was in contrast with the barbaric food culture of meat, lard and butter. Nevertheless, with the fall of the Roman Empire, an osmosis took place between the two, and that is how combining animal and plant products became the modern model for food consumption $[5,6]$.

The traditional MedDiet has been popularized since 1995 using a pyramid representation graphically highlighting the different food groups, with the base representing the foods to be eaten in the largest amounts and at the upper levels foods to be eaten in moderate amounts (i.e. daily, weekly or less frequently) [7]. Recently, a new graphic representation has been conceived as a simplified main frame to be adapted to the different nutritional and socio-economic contexts of the Mediterranean basin (fig. 1) [2].

\section{Dietary Habits in Sicily}

In the new syncretism between the Roman and Barbaric world, the Sicilian and Andalusian food culture differed from that of the rest of the European Mediterranean region, mostly due to the influence of the Arabs, who introduced flavours such as 'sweet and sour' and imported cane sugar and various other exotic and at the time virtually unknown spices to the Romans, such as cinnamon, ginger, cloves and nutmeg. These exotic herbs and spices are rich in essential oils and polyphenols (see below) and have added an array of flavours that still characterize Sicilian cuisine today. The Arabs were also responsible for the introduction of vegetables such as aubergines, artichokes, spinach and products such as dried pasta. These foods have become staples of the Sicilian diet. Other foods that are considered typically Sicilian, while not being indigenous, include red pepper, tomato and chili peppers; these were imported from America. Although sauces in general were a typical product of Roman cuisine, it was the Spanish who popularized tomato sauce, but the South Italians and Sicilians found it 'married' well with pasta and later with chili peppers also $[5,6]$.

The contribution of popular culture in the development of the Sicilian food model is particularly relevant, since the wealthy emphasized the role of meat and underestimated the produce of the land, considering it lowly and unworthy of their table. The humble countryside diet was traditionally characterized by plant foods, fresh fruit and extra virgin olive oil (EVOO, see below), the principal source of fat. Dairy products and poultry were consumed in low to moderate amounts (fish only by inhabitants on the coast), only about $0-4$ eggs per person were consumed weekly, red meat would have been scarcely available to the poorer country folk and was consumed in minimal amounts, while wine was readily available and consumed with meals on a regular basis $[2,5,8-11]$.

There is an area located on the western part of the island of Sicily where a very high presence of centenarians has been found. This area is called 'Monti Sicani' and is located between the provinces of Agrigento and Palermo. Monti Sicani encompasses the area between the cities of Palermo and Agrigento from North to South and between the city of Caltanissetta and Trapani from West to East. It is a hilly area of clay sandstone and pastures which is mountainous above $900 \mathrm{~m}$, and consists of pelagic limestone rocks of the Mesozoic. This area is rich in olive tree agriculture, which tolerates a large range of soil conditions, preferring a neutral to alkaline soil type [8-10].

Centenarians are equipped to reach the extreme limits of human lifespan and most importantly, to show relatively good health, representing a select group in which the appearance of major age-related diseases, such as cancer and cardiovascular diseases among others, has been consistently delayed or even avoided altogether. By studying centenarians, we are able to disentangle the genetic and environmental mechanisms responsible for reaching this positive phenotype, leading us to an understanding how to prevent and/or reduce age-related diseases [12].

Looking at the national ratio of centenarian per inhabitants, in this area, we have found more than a four-fold increase in centenarians, with a male-female ratio of 1.1:1 times. Previous studies have shown that the Sicilian male longevity is associated with an efficient genetic control of inflammatory responses [13]. Since the genetic 


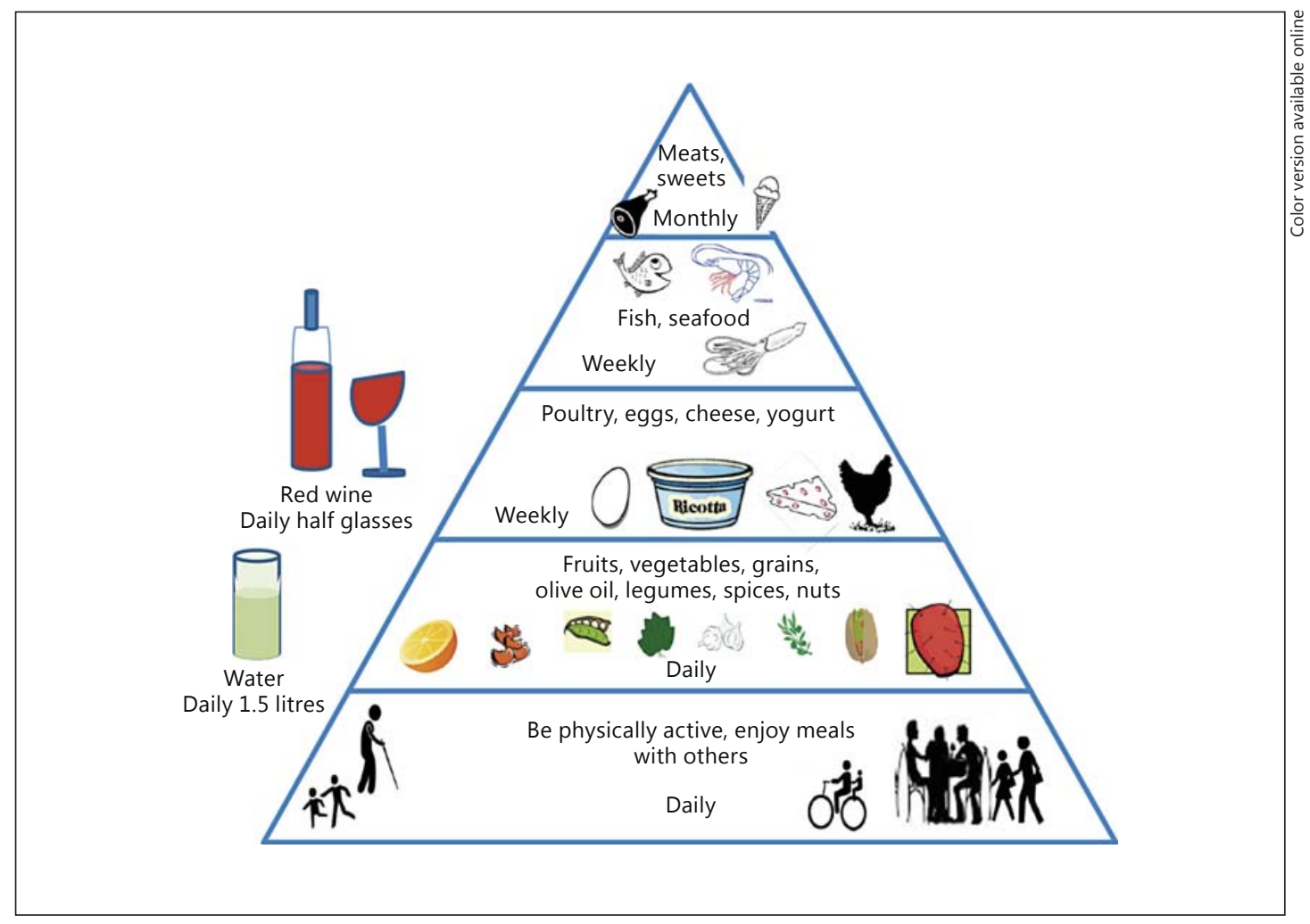

Fig. 1. Pyramid representation of the MedDiet. In this representation, everyday main meals should contain three basic elements: whole-grain cereals, vegetables and fruit. A daily intake of 1.5-2 litres of water should be guaranteed. Dairy products should be preferred in the form of low-fat yogurt, cheese and other fermented ones. In the middle of the pyramid, olive oil is located as the principal source of dietary lipids. A reasonable consumption of olives, nuts and seeds should be chosen for healthy snacks. Furthermore, herbs and spices can contribute either to the regional identities of Mediterranean dishes or to further nutrient supplementation such as 1 or 2 glasses per day of wine at the most,- depending on gender.

structure of the average Sicilian population is very homogeneous and in Hardy-Weinberg equilibrium, the explanation for these data probably lies in the environmental characteristics of the zone in question, taking into account the gene environment interaction $[8,9,12,13]$.

By examining this small yet significant segment of the population, the relevance of their dietary habits as well as their social living became very clear (all centenarians were found to be living or had lived with close relatives and family, mostly with their daughters). Their nutritional history reflected an upbringing in typical rural Sicilian areas, characterized by the frugal dietary patterns previously discussed, with a high percentage of seasonal plant
Every week, a variety of plant and animal origin proteins should be consumed (fish, white meat, eggs, legumes, whereas red meat should be consumed in smaller quantity and frequency). The top of the pyramid is represented by sugar, candies, pastries and sweet beverages such as sweet fruit juices and soft drinks that should be consumed occasionally and in small amounts. However, all portion sizes should be based on frugality in order to adopt a healthy lifestyle. So, at the bottom we find foods that should sustain the diet, and at the upper levels foods to be eaten in moderate amounts (i.e. daily, weekly or less frequently), reported according to nutritional habits of the Sicilian countryside (references in the text).

food and vegetables (mostly cabbage and chicory and bean consumption), and a lower-than-average consumption of animal products. Furthermore, in addition to the MedDiet triad, the typical centenarian diet has been found to be supplemented in moderation by milk and its derivatives, such as cheese and fresh ricotta, eggs, fruit (mostly apples and pears, but also seasonally available fruit such as prickly pears and oranges), with the principal supply of proteins provided by legumes. Their diet is hypocaloric with small and frequent meals, high in carbohydrate (whole wheat bread and pasta mostly topped with raw or cooked tomato) but with a low intake of refined carbohydrates, and an almost total proscription of red 
Table 1. Brief description of some foods characterizing Sicilian countryside dietary habits

\begin{tabular}{|c|c|c|c|c|}
\hline Food & $\begin{array}{l}\text { Main molecules } \\
\text { contained }\end{array}$ & $\begin{array}{l}\text { Main molecules } \\
\text { suggested to be active }\end{array}$ & Claimed effects in vivo or in vitro & Ref. \\
\hline Pistachio nuts & $\begin{array}{l}\text { vitamin C, vitamin E, trans-resveratrol, } \\
\text { isoflavones (daidzein and genistin), } \\
\text { proanthocyanidins, anthocyanins, } \\
\text { stilbenes and apigenin; } \\
\text { in pistachio skins (gallic acid, catechin, } \\
\text { epicatechin, eriodictyol-7-O-glucoside, } \\
\text { naringenin-7-O-neohesperidoside, } \\
\text { quercetin-3-O-rutinoside, eriodictyol, } \\
\text { quercetin, naringenin, luteolin, } \\
\text { kaempferol, cyanidin-3-O-galactoside } \\
\text { and cyanidin-3-O-glucoside) }\end{array}$ & $\begin{array}{l}\text { daidzein, genistin, } \\
\text { phenolic acid }\end{array}$ & $\begin{array}{l}\text { antioxidant properties } \\
\text { photoprotective, cardioprotective, } \\
\text { vasoprotective; inhibition of the } \\
\text { production of pro-inflammatory } \\
\text { cytokines, prostaglandins and NO }\end{array}$ & 27 \\
\hline $\begin{array}{l}\text { Prickly pear } \\
\text { fruit }\end{array}$ & $\begin{array}{l}\text { vitamin C, indicaxanthin, phenolics, } \\
\text { carotenoids, betalains, taurine, } \\
\text { flavonoids (quercetin, isorhamnetin, } \\
\text { kaempferol, luteolin, myricetin) }\end{array}$ & $\begin{array}{l}\text { flavonoid, ascorbic } \\
\text { acid, carotenoid, } \\
\text { betalains, } \\
\text { indicaxantin }\end{array}$ & $\begin{array}{l}\text { antioxidant and anti-inflammatory } \\
\text { properties; inhibition of the } \\
\text { production of pro-inflammatory } \\
\text { cytokines, prostaglandins and NO }\end{array}$ & 28 \\
\hline Oranges & $\begin{array}{l}\text { polyphenols (gallic acid), vitamin C, } \\
\text { anthocyanins (cyanidin-3-O-glucoside), } \\
\text { narirutin, hesperidin, carotenoids }\end{array}$ & narirutin, hesperidin & $\begin{array}{l}\text { anti-inflammatory, anti-endothelial } \\
\text { dysfunction; inhibition of the } \\
\text { production of pro-inflammatory } \\
\text { cytokines }\end{array}$ & 29 \\
\hline Capers & $\begin{array}{l}\text { vitamin E, carotenoids, vitamin C, } \\
\text { flavonoids (rutin, quercetin, kaempferol } \\
\text { 3-O-rutinoside, and isorhamnetin } \\
\text { 3-O-rutinoside) }\end{array}$ & flavonoids & $\begin{array}{l}\text { antifungal, anti-inflammatory, } \\
\text { antidiabetic, antihyperlipidemic }\end{array}$ & 30 \\
\hline Grapes & $\begin{array}{l}\text { cyanidin, peonidin, petunidin, } \\
\text { delphinidin and malvidin, quercetin and } \\
\text { myricetin, 3-glucosides of kaempferol, } \\
\text { isorhamnetin, laricitrin, syringetin, } \\
\text { catechin, (-)-epicatechin and } \\
\text { (-)-epicatechin-3-O-gallate, resveratrol }\end{array}$ & resveratrol & $\begin{array}{l}\text { anti-inflammatory, antioxidant, } \\
\text { antitumour and immunomodulatory } \\
\text { activities; in particular, resveratrol } \\
\text { reduces high-carbohydrate meal- } \\
\text { induced oxidative and inflammatory } \\
\text { stress }\end{array}$ & 31 \\
\hline Tomatoes & $\begin{array}{l}\text { lycopene, lutein, naringenin, rutin, } \\
\text { quercetin }\end{array}$ & lycopene & $\begin{array}{l}\text { prevention of prostate cancer, breast } \\
\text { cancer, liver diseases, cardiovascular } \\
\text { disease }\end{array}$ & 32 \\
\hline
\end{tabular}

meat and zero consumption of sweeteners or sweetened beverages, canned food, frozen already prepared vegetables or dishes, cookies, cakes or snacks, basically no processed foods. On the other hand, constant helpings of table olives, green and black, pickled or crushed, specifically the Giarraffa cultivar, are common. This variety, rich in essential fatty acids, constitutes an essential element for both the caloric intake $(135 \mathrm{kcal} / 100 \mathrm{~g}$ in green; $300 \mathrm{kcal} / 100 \mathrm{~g}$ in black) as well as for the completeness of the essential amino acids, the fibres and polyphenols [810]. Furthermore, seasonal intake of prickly pears, pistachios and oranges is likely to have added benefits and be responsible for the well-being and lifespan extension of this highly healthy segment of the population (see below and table 1).

Centenarians recruited in this area tended to be physically active. In fact, part of the rural lifestyle includes daily physical work combined with a natural diet. Physical activity acts synergistically with healthy diet in curbing inflammation. On the other hand, physical inactivity and a hypercaloric diet lead to an accumulation of visceral fat and adipose tissue infiltration by pro-inflammatory macrophages and $\mathrm{T}$ cells and in turn adipose tissue releases adipokines and pro-inflammatory cytokines. A persistent low-grade systemic inflammation will enhance the development of age-related inflammatory diseases. Athero-

$\begin{array}{ll} & \\ \text { Gerontology } \\ \text { DOI: } 10.1159 / 000363060\end{array}$


sclerosis is exacerbated by the deleterious changes in the blood lipid profile that are associated with a lack of physical activity. In addition, during exercise, muscle-derived interleukin (IL)-6 can increase plasma levels of the antiinflammatory cytokines IL-1ra and IL-10 [14].

In order to assess the general population's eating pattern preferences, the dietary habits of 1,297 adult Palermo residents were investigated [15]. A diet that could be defined as unhealthy was identified in $21 \%$ of the cohort, and was characterized by high consumption of soft drinks, fried foods, seed oils, cured meats, butter, red meat and sweets. Of the cohort, $34 \%$ exhibited a dietary pattern that resembled the MedDiet, characterized by high intakes of fruit, dairy, olive oil, vegetables, pasta and bread. Intermediate habits were found in the remaining $45 \%$ of the subjects. Interestingly, despite being about 10 years older on average than their unhealthy-food-eating counterparts, the MedDiet-like group did not have a higher prevalence of asymptomatic carotid atherosclerosis (intimamedia thickness $\geq 0.9 \mathrm{~mm}$ and/or presence of plaques). Multivariate analysis also showed that MedDiet-like habits were favourably associated with insulin sensitivity and high-density lipoproteins (HDL) concentrations. These data suggest that despite living in the Mediterranean area, not all inhabitants (only $34 \%$ of our cohort) of a big city really follow Mediterranean dietary habits. However, those who do eat a more traditional diet, have comparable carotid atherosclerosis, despite being an average of 10 years older than their unhealthy-food-eating counterparts, as if their biological age clock advanced more slowly [15].

We also need to consider that what we called MedDiet might be contaminated by other elements belonging to the socio-cultural area that we have been assessing. Accordingly, studying the usual dietary pattern of Palermo's inhabitants has demonstrated that street food is to be included as part of their dietary habits [16]. These are foods that have ancient, historical roots with complex socioeconomic and cultural implications. They are different foods prepared and/or sold by vendors in streets and other public places for immediate consumption or consumption at a later time without further processing or preparation. The main problem concerning the healthiness of street food is related to the way it is cooked. Most of this food tends to be fried and the cooking oil is cheaper seed oil and not the traditional EVOO. Other frying methods include the use of animal fats. Despite the emergence of modern fast food, traditional street food persists in Sicily. In this context, another recent study looked at more than 2,300 subjects in order to assess different aspects of street food consumption in Palermo. The study found eating street food frequently could be associated with higher body mass index values, higher prevalence of hypertension and also with higher uric acid and lower HDL cholesterol blood concentrations [16]. The collected data indicate that street food may have implications on health and due to its popularity as a widely consumed food needs to be accounted for when investigating individual or population dietary habits in Sicily, particularly in the bigger cities, such as Palermo. These data have demonstrated that, on the one hand, it is very important to consider the population dietary habits globally, while, on the other hand, it is very difficult to extrapolate the individual impact of foods consumption on health [16].

Hence, these data clearly indicate that in larger Sicilian cities there is less adherence to the MedDiet than in smaller countryside towns and villages, although in cities located along the coastline, people tend to consume more fish than in the countryside. This impacts the prevalence of age-related diseases and lifespan, hence, in Sicily, longevity concerns people living in the countryside rather than in big towns on the coast.

The idea that MedDiet plays a relevant role in the attainment of longevity in Sicily is in fact strengthened by data collected on the mortality rates of men and women after the age of 80 in various parts of the island. Longevity depends on specific mortality features between 80 and 100 years of age [17]. A decrease in the mortality rate with respect to diet pattern has been observed. In fact, longevity mostly affects the population living in small towns and mountain areas that follows a more ancient lifestyle with high adherence to MedDiet (it is noteworthy to repeat that the oldest old people have been found to be living with a close family, particularly with their own daughters). These areas also boast lower mortality rates from cardiovascular diseases in general $[10,17]$. On the contrary, in the big cities like Palermo, food choices have resulted in an increase in calories and a less healthy diet, proven by mortality rate due to cardiovascular diseases. Also, no increases in longevous people have been observed $[11,15,17]$.

\section{Biology of Ageing and Longevity}

Ageing can be defined as a decline in performance and fitness with advancing age, creating difficulty in adapting to new environmental situations. Ageing is not a programmed route but is a stochastic process resulting from accumulation of somatic damage, with a systemic loss of 
Fig. 2. Nutrient-sensing pathways modulate lifespan in humans by interacting with the environment. a Insulin/IGF-1 signalling pathway. Insulin (or IGF-1) binds its receptor (IRS) and interacts with PI3K. PI3K activates the second messenger PIP3. PIP3 messenger leads to the activation of AKT that inhibits FOXO3A, preventing the transcription of homeostatic genes. Also, SIRT1 can act on FOXO3A. Moreover, the insulin/IGF-1 signalling determines the activation of the RAS pathway leading to its mitogenic effect. In addition, AKT activates the NF-kB pathway allowing the transcription of inflammatory genes. MedDiet with low GI and/or with low protein intake may reduce the IGF-1 levels and may down-regulate the insulin/IGF-1 pathway leading to the transcription of homeostatic genes and stopping the mitogenic effect of RAS. This favours survival and longevity.

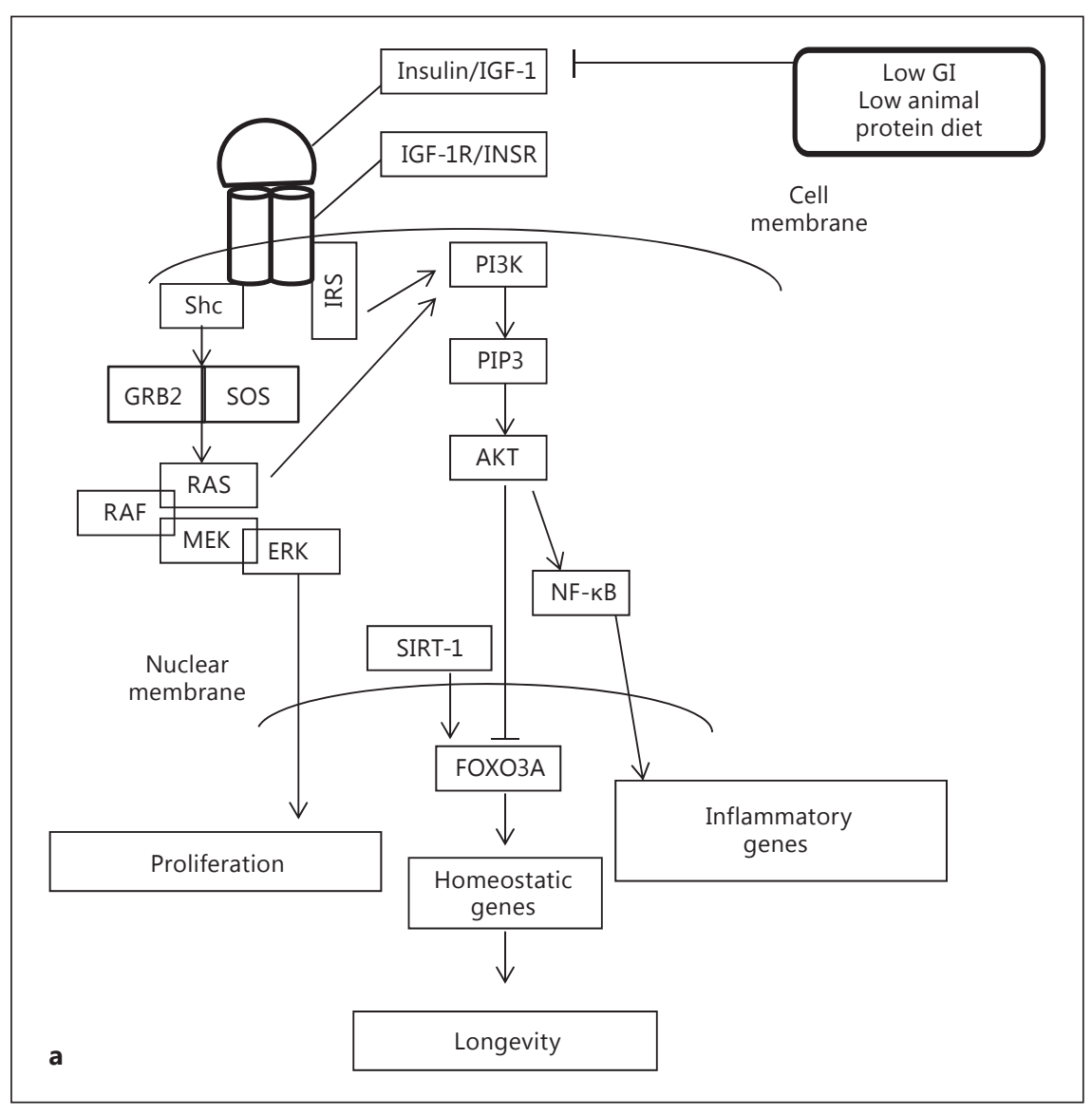

molecular fidelity, owing to limited investments in maintenance and repair that are evolutionarily selected to assure reproduction and parental care. Ageing is unnatural: damage is a fact of life due to a relative lack of the maintenance/repair system, including control of inflammation and oxidative stress $[18,19]$.

The ageing process and longevity are multifactorial events. Genetic, epigenetic, stochastic and environmental factors seem to have a crucial role in ageing and longevity. Researchers have found that approximately $25 \%$ of the overall variation in human lifespan can be attributed to genetic factors which become more relevant for extreme longevity. Conditioning factors, which arise in the first part of life, account for another $25 \%$ of such variability; life circumstances at adult and old age may account for about the remaining 50\% [12].

The ageing process is mostly stochastic, whereas the genome plays a role in determining longevity which is regulated by the level of functional reserve reached at the time of reproductive age through natural selection. In other words, the effect of the duration of life is incidental because the main effect of the genome is to govern the events that occur until reproductive maturity [20]. Thus it is not surprising that nutrient-sensing pathways, such as the insulin/insulin growth factor (IGF)-1 signalling and the mechanistic target of rapamycin (mTOR) ones, are the conserved genetic pathways modulating lifespan in model organisms such as yeast, worms, flies and mice [21, 22] (fig. 2a, b).

The insulin/IGF-1 pathway affects lifespan in model organisms and during evolution has diverged from a single to multiple receptors, increasing the level of complexity in mammals. However, a series of genetic manipulations in mice have provided evidence that this pathway also affects ageing and longevity in mammals. In humans, ageing is associated with lower IGF-1 circulating levels, and in longevous people its receptor (IGF-1R) has been correlated with modulation of human lifespan through the attenuation of IGF-1 signalling. The IGF-1 pathway downstream transcription factor, namely forkhead box

Gerontology
DOI: $10.1159 / 000363060$


Fig. 2. Nutrient-sensing pathways modulate lifespan in humans by interacting with environment. b mTOR pathway. AKT determines the inhibition of mTOR complexes. These molecules, via the activation of S6K, determine mRNA translation and protein synthesis with mitogenic and proinflammatory effects. Moreover, they inhibit the transcription of homeostatic genes (i.e. genes encoding antioxidant proteins such as catalase or superoxide dismutase or genes promoting autophagy). Dietary restriction, with low GI, low animal protein and a reduction in calorie intake, activates AMPK that inhibits mTORC1 favouring longevity. It means that MedDiet could influence longevity via mTORC1 and insulin/IGF-1 pathway down-regulation (references in the text). IRS = Insulin-responsive substrate; $\mathrm{PI} 3 \mathrm{~K}=$ phosphatidylinositol 3-kinase; PIP3 = phosphatidylinositol 3-phosphate; SIRT-1 = silent mating type information regulation 1 ; RAS = rat sarcoma; GI = glycaemic index.

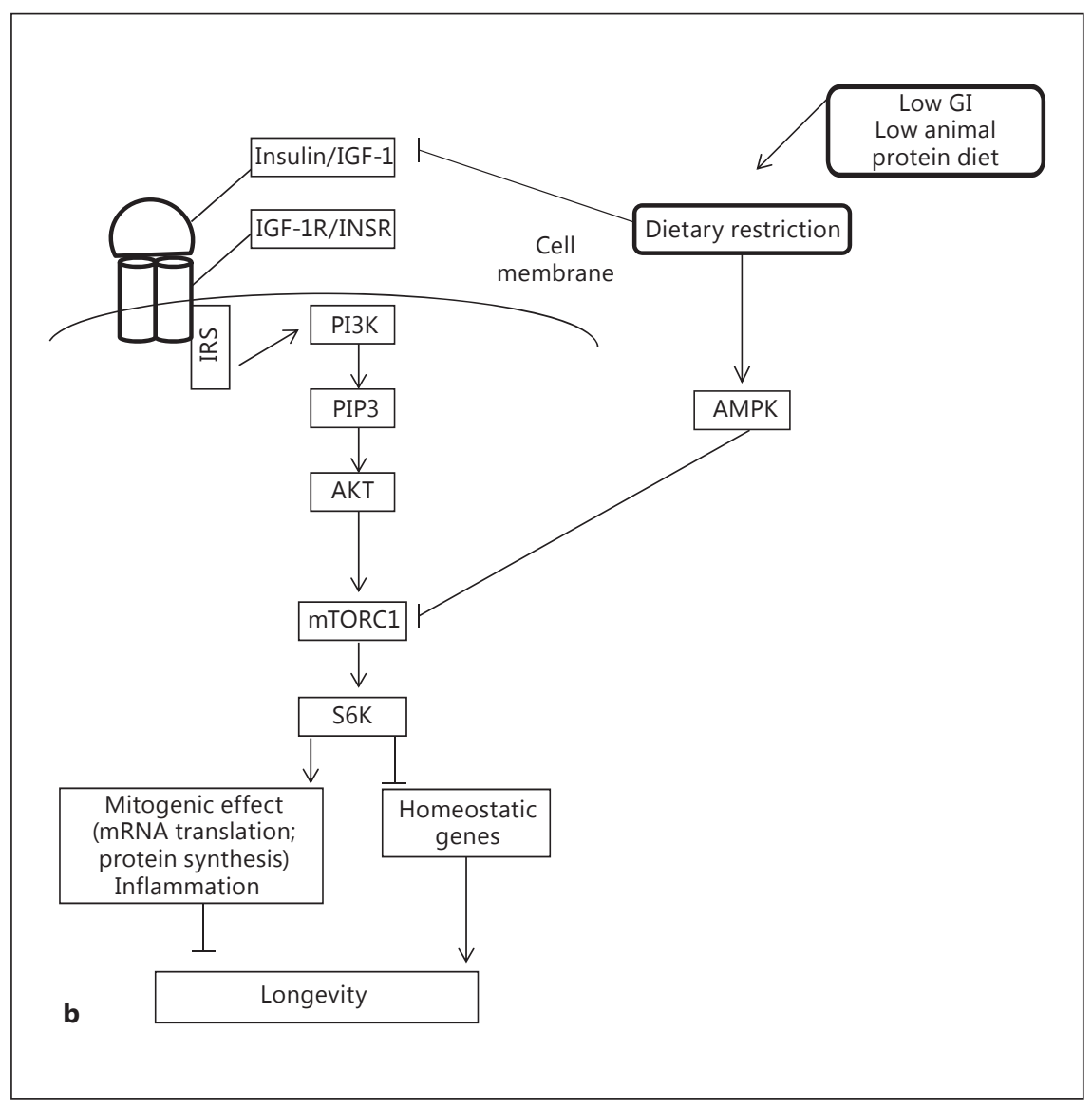

03A (FOXO3A), has also been extensively studied for its role in longevity. This gene belongs to the forkhead family and encodes a transcription factor with the typical forkhead box, a conserved DNA-binding domain. FOXO3A represents the orthologue of daf-16 in Caenorhabditis elegans which is involved in stress resistance and longevity [21]. In addition, FOXO3A interacts with sirtuins, a family of histone deacetylase enzymes, identified as anti-ageing molecules in different model organisms. SIRT1 acts through the deacetylation of FOXO3A in order to modulate its response to oxidative stress [23]. In animal models, the effects of this pathway on lifespan extension depend on their decreased activity which lead to a reduced phosphorylation of $d a f-16 /$ FOXO transcription factors that in turn increase their translocation to the nucleus and, consequently, their activity. Moreover, some studies have shown that polymorphisms in the genes encoding protein involved in the IGF-1 signalling pathway could influence human longevity, but the results of different studies are often inconsistent. Our recent systematic review and meta-analysis suggests that polymorphisms in both IGF-1R and FOXO3A genes are associated with longevity, likely allowing an increased activity of FOXO3A on downstream genes involved in survival [21].

The serine/threonine protein kinase, mTOR, belongs to the phosphatidylinositol-3OH kinase (PI3K)-related family. This kinase is a nutrient/hormone-sensing molecule that regulates cellular growth and metabolism, with mitogenic effects due to the promotion of protein synthesis and mRNA translation. Two distinct mTOR complexes exist, mTOR complex 1 (mTORC1) and mTOR complex 2 (mTORC2), more being known about the first one. This system is activated by insulin and other growth factors through the kinases PI3K and AKT and it is inhibited by AMP-activated protein kinase (AMPK), a key sensor of energy status activated in response to low ATP levels. Conversely, the down-regulation of the insulin pathway and the overexpression of AMPK lead to mTORC1 inhibition that has been linked to stress resistance and to a reduced chronic age-associated inflammation through 
the nuclear factor (NF)- $\kappa \mathrm{B}$ pathway (triggered by the activation of a protein complex that controls DNA transcription) $[22,24]$ involved in immune-inflammatory responses [25].

\section{Mediterranean Diet and Nutrient-Sensing Pathways}

It is well known that lifelong calorie restriction (CR) represents the only dietary intervention able to extend lifespan in model organisms including, to some extent, primates. CR is a dietary programme based on low calorie intake (30\% less than normal) but without any sign of malnutrition. The effect of CR on lifespan has been suggested to be linked to decreased IGF-1 circulating levels and consequently to the activation of FOXO3A and inhibition of mTORC1, inhibited also by AMPK activated in response to low ATP levels. Current available evidence strongly supports that anabolic signalling increases ageing speed, whereas reduction in nutrient signalling extends lifespan [24]. However, lifelong CR is difficult to realize in human beings, so it might be preferred to reach healthy ageing acting on modifying the quality of food intake through the diet.

A close adherence to MedDiet, as that performed in the Sicilian countryside, is a good candidate for it, due to its low animal protein and calorie intake. The low content of animal protein and the low glycaemic index of Sicilian MedDiet are able to directly modulate the insulin/IGF-1 and the mTOR pathways (fig. 2a, b). Epidemiological and experimental studies indicate that protein intake is one of the most important dietary regulators of circulating levels of IGF-1 which activates both sensing pathways. Consistently, an isocaloric reduction of protein intake significantly reduces serum IGF- 1 concentrations and inhibits mTOR activity, as indicated by a down-regulation of phosphorylated mTOR and p70-S6 kinase (S6K) in cell cultures $[22,24]$. Modulation of the insulin/IGF-1 pathway consists of the down-regulation of the signal that leads to the activation of FOXO3A and, consequently, to the transcription of homeostatic genes that favour longevity [21]. In addition, the down-regulation of both IGF1 and mTORC1 determines an anti-inflammatory effect [22].

On the other hand, high circulating levels of IGF-1 are associated with an increased risk of some cancers [24]. Moreover, the activation of the PI3K/AKT/mTOR pathway, through insulin/IGF-1 stimulation, plays a crucial role in maintaining the malignant phenotype, and its inhibition antagonized growth and motility of cancer cells in an experimental mouse model [24]. Down-regulation of $\mathrm{mTOR}$ activity and protein restriction were also associated with modulation of specific histone markers, suggesting an epigenetic modulation [24].

\section{Mediterranean Diet Nutrients, Phytochemicals and Hormesis}

In addition to the effects on sensing pathways, many single components of MedDiet are known to have positive effects on health, among others the abundance in mono/polyunsaturated fats, omega-3, low saturated fat, fibres, vitamins and minerals that play a role in reducing inflammation, optimizing cholesterol and other risk factors important in age-related diseases $[11,26]$.

Moreover, MedDiet has been claimed to offer phytochemicals, i.e. plant chemicals that may have biological significance as antioxidants and anti-inflammatories. Natural antioxidants contained in plant-based extracts are in fact under study and are of interest to both food scientists and clinicians. There are several studies revealing a positive correlation between a diet rich in plantbased food and a reduced risk of diseases associated with oxidative stress. Natural antioxidants from dietary sources include phenolic and polyphenolic compounds, chelators, antioxidant vitamins and enzymes as well as carotenoids $[11,26]$.

Table 1 reports a brief description of some foods characterizing Sicilian countryside dietary habits [27-32]. As previously stated, olive oil plays a central role in MedDiet $[2,11,33-35]$ and a glass of wine with meals may be assumed every day $[2,11]$. Alcohol, in moderation, especially red wine, has nutritional and heart-protective benefits. This protective effect has been associated with an increase in HDL plasma level. Flavonoids (see below) in red wine have been claimed to offer benefit in the prevention of cardiovascular diseases by inhibiting low-density lipoprotein (LDL) oxidation, reducing thrombosis, improving endothelial function, and reducing inflammation [36]. The effects of polyphenol resveratrol are reported in table 1. It is noteworthy that one of the most widespread cultivars in Sicily, 'Nero d'Avola', is very rich in flavonoids and resveratrol.

About EVOO, it is used for cooking and as a dressing mostly in the countryside. It is the juice of the olive solely obtained by a mechanical procedure and consumed after washing, filtration and decantation or centrifugation, without the use of any solvents, and under controlled temperatures that will not harm the oil $\left(<30^{\circ} \mathrm{C}\right)$ [33]. Tra- 
ditionally, the health effects of EVOO are attributed to its high content in oleic acid, a monounsaturated fatty acid that reduces LDL cholesterol levels in comparison to saturated fats. However, it includes minor functional components such as aliphatic and triterpenic alcohols, sterols, hydrocarbons, tocopherols and carotenes [33, 34]. Moreover, it has been demonstrated that the phenolic fraction represents the most abundant family of bioactive EVOO compounds. More than 36 phenolic compounds have been identified in EVOO in different concentrations and compositions $(0.02-600 \mathrm{mg} / \mathrm{kg})$, depending on the variety, growing region, agricultural techniques, maturity at harvest and processing of the olive fruit [33]. In general, four major classes of phenols can be found in EVOO, i.e. flavonoids, lignans, simple phenols (oleocanthal and hydroxytyrosol that inhibit the cyclooxygenases 1 and 2 responsible for prostaglandin production, in a dose-dependent manner) and secoiridoids (oleuropein, that seemingly serves as scavenger, blocking LDL oxidation) [33-35].

Polyphenols, represented in high amounts of all Mediterranean vegetables and fruits, are naturally occurring phytochemicals characterized by the presence of multiple hydroxyl groups on aromatic rings. In plants they are involved in the defence from pathogen attacks or stress induced by chemical and physical damage. The health benefits of polyphenols are assumed to be due to their ability to work as free radical scavengers, i.e. to perform an antioxidant activity $[3,26]$, but most polyphenols have very limited bioavailability, being largely metabolized [37]. However, they may exert a local antioxidant activity in the gastrointestinal tract [11] preventing local cancer.

New data have suggested that low amounts of polyphenols, as those present in foods, act as hormetins, i.e. they are able to activate cellular stress response pathways, as for example the nuclear factor erythroid 2-related factor 2 (Nrf2). Nrf2 is translocated to the nucleus, activating genes that encode antioxidant enzymes (such as isothiocyanates in Brassicaceae like broccoli, cabbage, and cauliflower). Polyphenols can also regulate the transcription factor NF- $\kappa$ B by reducing the expression of inflammatory cytokines and they can activate SIRT1 (such as resveratrol in grapes and red wine and secoiridoids in EVOO) that may also inhibit NF- $\mathrm{kB}$, reducing the cellular stress response $[35,37-39]$. On the other hand, SIRT1 acts on FOXO3A, which, as previously stated, modulates genes that encode antioxidant enzymes and other stress-response proteins [21].

It is becoming clear that, throughout human history, diet has affected the expression of genes, resulting in phe- notypes that are able to successfully respond to environmental challenges, hence allowing better utilization of food resources [40]. Environmental stimuli, including diet, are responsible for epigenetic modifications which alter gene expression. An extensive study conducted on cohorts of newborns, nonagenarians and middle-aged adults has demonstrated that, with age, there is a progressive hypomethylation of the genome that may be responsible for age-related changes of gene expression [41].

In particular, as recently reviewed, phytochemicals and nutrients are able to influence the expression of miRNAs, a class of evolutionarily conserved small non-coding RNAs of 19-24 nucleotides that, in turn, regulate gene expression mostly at the post-transcriptional level, suppressing translation and/or reducing the stability of their target mRNAs [42]. Several polyphenols have been shown to modulate miRNAs related to metabolic homeostasis and chronic diseases. Evidence is building that polyphenols can target specific miRNAs, but more studies are necessary to discover and validate miRNA targets [43]. In vitro studies on miRNA modulation by polyphenols have been performed in monocyte and macrophage systems and polyphenols including resveratrol, quercetin, and isorhamnetin studied in macrophages mainly target miR155 which, in turn, plays a role as a pro-inflammatory factor [44].

\section{Conclusion}

MedDiet is linked to a historical more than a geographical tradition and thus varies not only in different cities and villages but also between different social classes. In any case, diet means lifestyle and culture, not a simple nutrition prescription. Thus, other lifestyle-related factors, such as family-based meals, socialization, adequate rest and sleep and physical activity, can significantly alter the effect of the diet on morbidity and mortality.

What characterizes the Sicilian countryside way of eating is the approach to food, where eating patterns are marked by certain forms of sociability centred on the three daily meals which follow certain rituals marking respect for food and 'food culture'.

In conclusion, the close adherence to the MedDiet is responsible for the high rate of long-living individuals in circumscribed parts of Sicily. As previously stated, this is linked to diet effects on sensing pathways and to the synergistic action of nutraceutical components of MedDiet known to positively affect health. MedDiet is in fact rich in plant chemicals that act as antioxidants and anti-in- 
flammatories (phytochemicals), some of them more present in Sicilian diet that in other ones. It implies a daily dose of micronutrients as well as phytochemicals that protect people from the main age-related diseases.

\section{Acknowledgement}

Supported by PON DIMESA (valorization of typical products of the Mediterranean diet and their nutraceutical use to improve health).

\section{References}

1 Trichopoulou A: Diversity vs. globalization: traditional foods at the epicentre. Public Health Nutr 2012;15:951-954.

2 Bach-Faig A, Berry EM, Lairon D, Reguant J, Trichopoulou A, Dernini S, Medina FX, Battino M, Belahsen R, Miranda G, Serra-Majem L; Mediterranean Diet Foundation Expert Group: Mediterranean diet pyramid today. Science and cultural updates. Public Health Nutr 2011;14:2274-2284.

3 Keys A, Menotti A, Karvonen MJ, Aravanis C, Blackburn H, Buzina R, Diordjevlc BS, Dontas AS, Fidanza F, Keys MH, Kromhout D, Nedeljkovic S, Punsar S, Seccareccia F, Toshima H: The diet and 15-year death rate in the seven countries study. Am J Epidemiol 1986; 124:903-915.

4 Estruch R, Ros E, Salas-Salvadó J, Covas MI, Corella D, Arós F, Gómez-Gracia E, RuizGutiérrez V, Fiol M, Lapetra J, LamuelaRaventos RM, Serra-Majem L, Pintó X, Basora J, Muñoz MA, Sorlí JV, Martínez JA, Martínez-González MA; PREDIMED Study Investigators. Primary prevention of cardiovascular disease with a Mediterranean diet. $\mathrm{N}$ Engl J Med 2013;368:1279-1290.

5 Montanari M: Continuità e rotture, incorporazioni, diversificazioni: il Mediterraneo e la sua 'dieta' come realtà storica mutevole, in Scritti di storia medievale offerti a Maria Consiglia De Matteis, a cura di B. Pio, Spoleto, Centro italiano di studi sull'Alto Medioevo 2011, pp 479-492.

6 Montanari M (ed): L'identità della cucina Italiana. Bari, Laterza, 2010.

7 Willett WC, Sacks F, Trichopoulou A, Drescher G, Ferro-Luzzi A, Helsing E, Trichopoulos D: Mediterranean diet pyramid: a cultural model for healthy eating. Am J Clin Nutr 1995;61:1402S-1406S

8 Vasto S, Rizzo C, Caruso C: Centenarians and diet: what they eat in the Western part of Sicily. Immun Ageing 2012;9:10,

9 Vasto S, Scapagnini G, Rizzo C, Monastero R, Marchese A, Caruso C: Mediterranean diet and longevity in Sicily: survey in a Sicani Mountains population. Rejuvenation Res 2012;15:184-188.

10 Marchese AG (ed): La quarta età tra umanesimo letterario e biomedicina. Indagine sulla longevità nei Monti Sicani. Palermo, Palma, 2011.
11 Vasto S, Di Carlo M, Caruso C, Panotopoulos G: Mediterranean diet and longevity: an example of nutraceuticals? Curr Vascular Res 2014 (Epub ahead of print).

12 Caruso C, Passarino G, Puca A, Scapagnini G 'Positive biology': the centenarian lesson. Immun Ageing 2012;9:5.

13 Incalcaterra E, Accardi G, Balistreri CR, Caimi G, Candore G, Caruso M, Caruso C: Proinflammatory genetic markers of atherosclerosis. Curr Atheroscler Rep 2013;15:329.

14 Gleeson M, Bishop NC, Stensel DJ, Lindley MR, Mastana SS, Nimmo MA: The anti-inflammatory effects of exercise: mechanisms and implications for the prevention and treatment of disease. Nat Rev Immunol 2011;11 607-615.

15 Buscemi S, Nicolucci A, Mattina A, Rosafio G, Massenti FM, Lucisano G, Galvano F, Amodio E, Pellegrini F, Barile AM, Maniaci V, Grosso G, Verga S, Sprini D, Rini GB: Association of dietary patterns with insulin resistance and clinically silent carotid atherosclerosis in apparently healthy people. Eur J Clin Nutr 2013;67:1284-1290.

16 Buscemi S, Barile A, Maniaci V, Batsis JA, Mattina A, Verga S: Characterization of street food consumption in Palermo: possible effects on health. Nutr J 2011;10:119.

17 Bürkle A, Caselli G, Franceschi C, Mariani E, Sansoni P, Santoni A, Vecchio G, Witkowski JM, Caruso C: Pathophysiology of ageing, longevity and age-related diseases. Immun Ageing 2007;4:4.

18 Vasto S, Candore G, Balistreri CR, Caruso M Colonna-Romano G, Grimaldi MP, Listi F, Nuzzo D, Lio D, Caruso C: Inflammatory networks in ageing, age-related diseases and longevity. Mech Ageing Dev 2007;128:83-91.

19 Kirkwood TB: Understanding ageing from an evolutionary perspective. J Intern Med 2008; 263:117-127.

20 Hayflick L: Entropy explains aging, genetic determinism explains longevity, and undefined terminology explains misunderstanding both. PLoS Genet 2007;3:e220.

21 Di Bona D, Accardi G, Virruso C, Candore G, Caruso C: Association between genetic variations in the insulin/insulin-like growth factor (IGF-1) signaling pathway and longevity: a systematic review and meta-analysis. Curr Vasc Pharmacol 2014 (Epub ahead of print).

22 López-Otín C, Blasco MA, Partridge L, Serrano $\mathrm{M}$, Kroemer $\mathrm{G}$ : The hallmarks of aging. Cell 2013;153:1194-1217.
23 Guarente L, Franklin H: Epstein lecture: sirtuins, aging, and medicine. $\mathrm{N}$ Engl $\mathrm{J}$ Med 2011;364:2235-2444.

24 Fontana L, Adelaiye RM, Rastelli AL, Miles KM, Ciamporcero E, Longo VD, Nguyen $H$, Vessella R, Pili R: Dietary protein restriction inhibits tumor growth in human xenograft models. Oncotarget 2013;4:2451-2461.

25 Balistreri CR, Candore G, Accardi G, Colonna-Romano G, Lio D: NF- $\kappa$ B pathway activators as potential ageing biomarkers: targets for new therapeutic strategies. Immun Ageing 2013;10:24.

26 Ortega R: Importance of functional foods in the Mediterranean diet. Public Health Nutr 2006;9:1136-1140.

27 Gentile C, Allegra M, Angileri F, Pintaudi AM, Livrea MA, Tesoriere L: Polymeric proanthocyanidins from Sicilian pistachio (Pistacia vera L.) nut extract inhibit lipopolysaccharide-induced inflammatory response in RAW 264.7 cells. Eur J Nutr 2012;51:353-363.

28 Allegra M, Ianaro A, Tersigni M, Panza E, Tesoriere L, Livrea MA: Indicaxanthin from cactus pear fruit exerts anti-inflammatory effects in carrageenin-induced rat pleurisy. J Nutr 2014;144:185-192.

29 Buscemi S, Rosafio G, Arcoleo G, Mattina A, Canino B, Montana M, Verga S, Rini G: Effects of red orange juice intake on endothelial function and inflammatory markers in adult subjects with increased cardiovascular risk. Am J Clin Nutr 2012;95:1089-1095.

30 Tesoriere L, Butera D, Gentile C, Livrea MA: Bioactive components of caper (Capparis spinosa L.) from Sicily and antioxidant effects in a red meat simulated gastric digestion. J Agric Food Chem 2007;55:8465-8471.

31 Nassiri-Asl M, Hosseinzadeh H: Review of the pharmacological effects of Vitis vinifera (grape) and its bioactive compounds. Phytother Res 2009;23:1197-1204.

32 Ip BC, Wang XD: Non-alcoholic steatohepatitis and hepatocellular carcinoma: implications for lycopene intervention. Nutrients 2013;6:124-162.

33 Virruso C, Accardi G, Colonna Romano G, Candore G, Vasto S, Caruso C: Nutraceutical properties of extra virgin olive oil: a natural remedy for age-related disease? Rejuvenation Res 2014; 17:217-220. 
34 Menendez JA, Joven J, Aragonès G, BarrajónCatalán E, Beltrán-Debón R, Borrás-Linares I, Camps J, Corominas-Faja B, Cufí S, Fernández-Arroyo S, Garcia-Heredia A, HernándezAguilera A, Herranz-López M, Jiménez-Sánchez C, López-Bonet E, Lozano-Sánchez J, Luciano-Mateo F, Martin-Castillo B, MartinParedero V, Pérez-Sánchez A, Oliveras-Ferraros $\mathrm{C}$, Riera-Borrull $\mathrm{M}$, Rodríguez-Gallego E, Quirantes-Piné R, Rull A, Tomás-Menor L, Vazquez-Martin A, Alonso-Villaverde C, Micol V, Segura-Carretero A: Xenohormetic and anti-aging activity of secoiridoid polyphenols present in extra virgin olive oil: a new family of gerosuppressant agents. Cell Cycle 2013;12: 555-578.

35 Martín-Peláez S, Covas MI, Fitó M, Kušar A, Pravst I: Health effects of olive oil polyphenols: recent advances and possibilities for the use of health claims. Mol Nutr Food Res 2013; 57:760-771.
36 Whayne TF Jr, Maulik N: Nutrition and the healthy heart with an exercise boost. Can J Physiol Pharmacol 2012;90:967-976.

37 Vauzour D: Dietary polyphenols as modulators of brain functions: biological actions and molecular mechanisms underpinning their beneficial effects. Oxid Med Cell Longev 2012;2012:914273.

38 Mann GE, Rowlands DJ, Li FY, de Winter P, Siow RC: Activation of endothelial nitric oxide synthase by dietary isoflavones: role of NO in Nrf2-mediated antioxidant gene expression. Cardiovasc Res 2007;75:261-274.

39 Scapagnini G, Vasto S, Abraham NG, Caruso C, Zella D, Fabio G: Modulation of Nrf2/ARE pathway by food polyphenols: a nutritional neuroprotective strategy for cognitive and neurodegenerative disorders. Mol Neurobiol 2011;44:192-201.

40 Bouchard C, Ordovas JM: Fundamentals of nutrigenetics and nutrigenomics. Prog Mol Biol Transl Sci 2012;108:1-15.
41 Heyn H, Li N, Ferreira HJ, Moran S, Pisano DG, Gomez A, Diez J, Sanchez-Mut JV, Setien F, Carmona FJ, Puca AA, Sayols S, Pujana MA, Serra-Musach J, Iglesias-Platas I, Formiga F, Fernandez AF, Fraga MF, Heath SC, Valencia A, Gut IG, Wang J, Esteller M: Distinct DNA methylomes of newborns and centenarians. Proc Natl Acad Sci USA 2012;109: 10522-10527.

42 García-Segura L, Pérez-Andrade M, Miranda-Ríos J: The emerging role of microRNAs in the regulation of gene expression by nutrients. J Nutrigenet Nutrigenomics 2013;6:1631.

43 Qiu Z, Dai Y: Roadmap of miR-122-related clinical application from bench to bedside. Expert Opin Investig Drugs 2014;23:347-355. 44 Sonkoly E, Pivarcsi A: MicroRNAs in Inflammation. Int Rev Immunol 2009;28: 535-561.

\section{(C) Free Author Copy - for personal use only}

ANY DISTRIBUTION OF THIS ARTICLE WITHOUT WRITTEN CONSENT FROMS. KARGER AG, BASEL IS A VIOLATION OF THE COPYRIGHT.

Written permission to distribute the PDF will be granted against payment of a permission fee, which is based on the number of accesses required. Please contact permission@karger.ch 